American Journal of Applied Sciences 7 (7): 892-901, 2010

ISSN 1546-9239

(C) 2010 Science Publications

\title{
Synthesis and Characterization of Silver/Polyvinilpirrolidone (Ag/PVP) Nanoparticles Using Gamma Irradiation Techniques
}

\author{
${ }^{1}$ Shawkat Salameh Gasaymeh, ${ }^{1}$ Shahidan Radiman, ${ }^{2}$ Lee Yook Heng, \\ ${ }^{3}$ Elias Saion and ${ }^{1}$ G.H. Mohamed Saeed \\ ${ }^{1}$ Department of Nuclear Science, Faculty of Science and Technology, School of Applied Physics, \\ University of Kebangsaan Malaysia (UKM), Bangi-43600 Selangor, Malaysia \\ ${ }^{2}$ Faculty of Science and Technology, School of Chemistry and Food Science, \\ UKM-43600 Bangi Selangor, Malaysia \\ ${ }^{3}$ Department of Applied Physics, Faculty of Science, Putra University, \\ UPM-43400 Serdang, Selangor Malaysia
}

\begin{abstract}
Problem statement: In this study, attempts had been made to synthesize silver (Ag)/Poly Vinylpyrolidone (PVP) nanoparticles by ionizing radiation and at the same time overcoming some of the disadvantages previously reported by other methods such as impurities, solvent toxicity, size and distribution control and difficulty in their preparation that limits their commercialization potential. Approach: The use of this alternative method overcomes some unfavorable characteristics like long tedious and costly process, uncontrolled size and distribution. The advantages of radiation processing of the materials relative to other methods are; no metallic catalyst is required; (gives pure product), no oxidizing or reducing agent is required, the process occurs at a liquid or/and solid-state condition, fast and inexpensive, environmental friendly with controllable acquisitions. Results: Ag/PVP nanoparticles were successfully prepared in one-step by $\gamma$-irradiation technique in an aqueous system at room temperature and under ambient pressure. The Transmission of Electron Microscopy (TEM) of the asprepared product particles ranged from 100 to around $8 \mathrm{~nm}$ depend on the irradiation dose value, which showed a good distribution with a controlled size as dose changed. The presence of PVP polymer was considered as an important reason that influenced the shape and distribution. The band gap energy was calculated from the UV-VIS absorption spectra. Thermal analysis TGA showed that the composite had a higher degradation temperature than the PVP alone. Conclusion: This result indicated that $\mathrm{AgNO}_{3}$ can effectively dope PVP and enhance the optical and thermal properties. In addition, $\gamma$-irradiation is an effective technique for preparing inorganic/organic nanocomposites.
\end{abstract}

Key words: Ag/PVP, Band gap energy, TEM, thermal properties, gamma irradiation

\section{INTRODUCTION}

The nanoscale metal particles such as silver and gold provide a very exciting research field because of their interesting optical, electronic, magnetic and catalytic properties. The metal nanoparticles, therefore, have potential uses in technological applications. Silver exhibits the highest electrical and thermal conductivities among all the metals (Khanna et al., 2005a).

Ag metal nanoparticle/organic polymer composites have attracted considerable interest in recent years because of the advantageous properties of metals and polymers built into them. Many methods have been developed for the fabrication of the metal/polymer nanocomposites. However, the major disadvantages in the preparation of polymer metal nanocomposites by some methods are the poor distribution of the inorganic nanoparticle size and the poor dispersion of the inorganic particles in the polymer host and the use of toxic material for reduction of metal. In these methods, the formations of the polymer matrix and inorganic nanoparticles are performed in two separated steps. Therefore, it is difficult to avoid both the phases of separation and the aggregation of small particles. In addition, a heat treatment or high pressure is necessary in such conditions, which makes the preparing procedure more complex and difficult.

Corresponding Author: Shawkat Salameh Gasaymeh, Department of Nuclear Science, Faculty of Science and Technology, School of Applied Physics, The National University of Malyasia, 43600 UKM Bangi Selangor, Malaysia Tel: +60173928906 
Gamma-irradiation has been successfully used to prepare nanocrystalline nanometer-size; metal/polymer nanocomposites have been prepared with a one-step synthesis with $\gamma$-irradiation in aqueous solutions (Karim et al., 2007; Qiao et al., 1999; 2000; Jan et al., 2004), with detailed of characterization. A possible mechanism of the formation of $\mathrm{Ag}$ nanoparticles by gamma irradiation system is proposed in scheme 1 . The color of the irradiated samples were changed from colorless before irradiation to yellow or golden yellow to darker in color as the dose increases. This result may be due to the reduction of $\mathrm{AgNO}_{3}$ to $\mathrm{Ag}$ nanoparticles in PVP matrix that acts as a binder or protective agent, which restricts the mobility of the $\mathrm{Ag}$ ions during chemical reaction, prevents aggregation among the $\mathrm{Ag}$ nanoparticles and limits the size of $\mathrm{Ag}$ nanoparticles (Bogle et al., 2006; Khanna et al., 2005b). Gamma irradiation offers many advantages for the preparation of metal nanoparticles. Large number of hydrated electrons produced during $\gamma$-ray irradiation can reduce the metal ions to zero valiant metal particles (Kang et al., 2006). A summation made by (Virk and Srivastava, 2001; Singh et al., 2008) suggested that; irradiations cause a chemical change in polymers, including cross linking, chain scission, formation of $\mathrm{C}=\mathrm{C}$, formation of alkyne groups, depletion of heteroatoms, (e.g., N, S or O). In addition, an extensive study done by (Steckenreiter et al., 1997) on polycarbonate via irradiation-induced found the same result that irradiation induces conductivity and enhances their thermal properties. The effect of gamma irradiation, neutron, ion or e-beams on polycarbonate is primarily chain scission.

In recent years, studies on the electrical and optical properties of polymers have attracted much attention in view of their application in optical devices. The optical properties of polymers can be suitably modified by the addition of dopants depending on their reactivity with the host matrix. Although some studies have reported on the charge carrier transport and optical properties of doped polymers, but to the best of our knowledge no work is available on doped PVP. PVP is a potential material in which its dielectric strength is very high; furthermore, it is a good charge storage capacity and dopant-dependent optical properties. Since $\mathrm{AgNO}_{3}$ is a fast conducting ion in a number of crystalline and amorphous materials, its incorporation within a polymeric system may be expected to enhance its electrical and optical performance.

The incorporation of inorganic/organic is believed to remarkably improve a wide range of properties of the polymers due to the nanosized dispersion (Basavaraja et al., 2008a). Among these properties, the enhancement of thermal property is one that has been observed in many polymer nanocomposites (Basavaraja et al., 2008b). It was reported that incorporation of inorganic/organic significantly elevates the glass transition temperature and the degradation temperature of the neat polymer (Park et al., 2002; Lebaron et al., 1999; Baughman et al., 1988). In this study, we extend the above $\gamma$-irradiation method to the synthesis of Ag/PVP nanocomposites in an aqueous solution. TEM observations showed that the $\mathrm{Ag}$ nanoparticles with smaller size and with a well distribution were obtained at higher dose. The UV-VIS spectra of the nanocomposite were also studied to calculate the optical band gap energy.

\section{MATERIALS AND METHODS}

Silver nitrate $\left(\mathrm{AgNO}_{3}\right)$, Polyvinilpirrolidone PVP $\mathrm{Mw}=10,000$ (Aldrich) and other chemicals were used as received. Deionized water was prepared in the laboratory, Isopropyl Alcohol (IPA) was used as radical scavenger in all samples.

Ag/PVP nanoparticles have been synthesized by using $\gamma$-irradiation process. For this purpose, procedures were done in a clean room, with appropriate amount of $\mathrm{AgNO}_{3}$ and PVP were dissolved in deionized water separately as illustrated and tabulated in Scheme 1 and maintained under vigorous stirring until a homogeneous solution was obtained. Then the two solutions were added to each other under vigorous stirring for $1 \mathrm{~h}$ with the presence of IPA. The initially homogeneous solution was bubbled with nitrogen for half an hour before irradiation. In order to study the effect of $\gamma$ irradiation on the mixture, five samples were sealed and sent to Gamma cell to be irradiated at different dose ranging from $10-50 \mathrm{kGy}$ in a step of $10 \mathrm{kGy}$. It is important to note that the quantity of PVP, IPA and water were $0.5 \mathrm{~g}, 5$ and $50 \mathrm{~mL}$ respectively in all the samples. Moreover, the effect of $\mathrm{AgNO}_{3}$ concentration was also studded as shown in Scheme 1.

The mixture was prepared and stirred in a dark room at room temperature, preventing UV radiation of the environment from reducing $\mathrm{AgNO}_{3}$ into silver nanoparticles before the treatment with $\gamma$-radiation. The purified yellow or/and the dark golden precipitate was centrifuged and washed in deionized water and ethanol several times to be ready for examination through different instruments. It is important to mention the color of the $\mathrm{Ag}$ nanoparticles solution is yellow and goes to darker as dose increase or/and as the concentration of $\mathrm{AgNO}_{3}$ increase which indicates to more reduction of $\mathrm{AgNO}_{3}$ to $\mathrm{Ag}$ nanoparticles. 


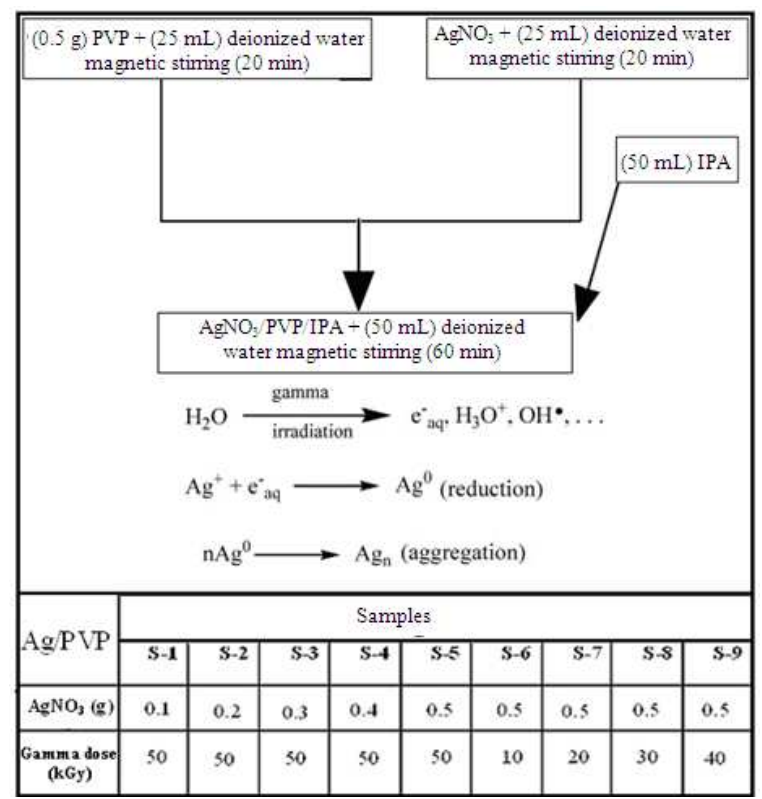

Scheme 1: The procedures and the quantity of the prepared Ag/PVP nanoparticles with a proposed formation of $\mathrm{Ag}$ nanoparticles

\section{RESULTS}

Effect of gamma irradiation and $\mathrm{AgNO}_{3}$ concentration on the Morphology by TEM and STEM: In order to study the effect of irradiation dose on the reduction of $\mathrm{AgNO}_{3}$ to $\mathrm{Ag}$ nanoparticles in PVP solution, TEM images at different dose was taken for $\mathrm{Ag} / \mathrm{PVP}$ nanocomposites. The result reveals that higher gamma dose will lead to more reduction of $\mathrm{AgNO}_{3}$ to $\mathrm{Ag}$ nanoparticles in PVP solution and the formation of smaller particles is clear with better distribution.

The function of PVP in the Ag/PVP composites is not only as a binder but it prevents the process of agglomeration of Ag nanoparticles (Bogle et al., 2006; Kang et al., 2006) and limits the diameter of the nanoparticles that are formed, as mentioned above. The polymer was used in this study due to its hydrophilic nature of PVP that protects the surface of the $\mathrm{Ag}$ nanoparticles. The average particle size of $\mathrm{Ag} / \mathrm{PVP}$ at different dose with a fixed amount of $0.3 \mathrm{~g}$ of $\mathrm{AgNO}_{3}$ in our experiment was estimated to be ranging from around $6 \mathrm{~nm}$ at $50 \mathrm{kGy}$ with well distribution to about $100 \mathrm{~nm}$ at $10 \mathrm{kGy}$ with irregular shapes, as shown in Fig. 1 and 2, respectively.

Moreover, the effect of molar ratio of $\mathrm{AgNO}_{3}$ to PVP was observed by STEM and TEM, which reveals that as $\mathrm{AgNO}_{3}$ concentration is increased in the system, the size goes larger with an irregular shape.

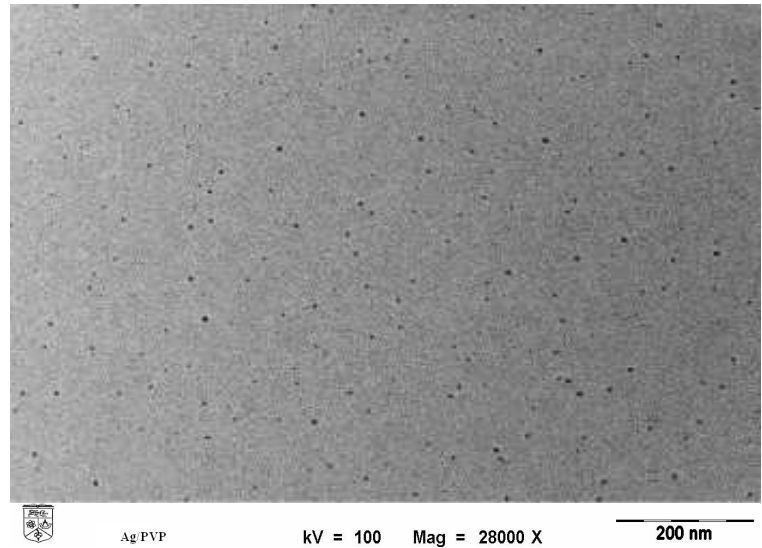

Fig. 1: TEM micrograph of $\mathrm{Ag}$ nanoparticles in PVP prepared at $50 \mathrm{kGy}$ with $0.3 \mathrm{~g}$ of $\mathrm{AgNO}_{3}$

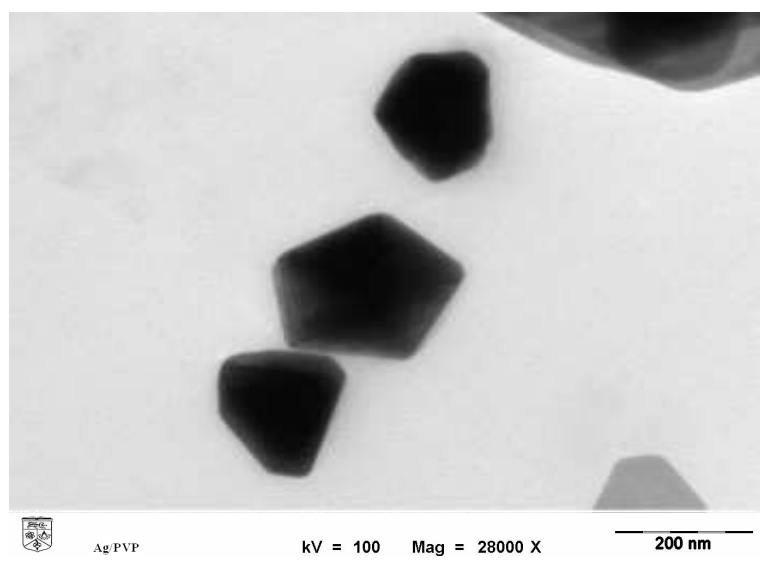

Fig. 2: TEM micrograph of Ag nanoparticles in PVP solution prepared at $10 \mathrm{kGy}$ with $0.3 \mathrm{~g}$ of $\mathrm{AgNO}_{3}$

The average particle size of $\mathrm{Ag} / \mathrm{PVP}$ prepared at 40 $\mathrm{kGy}$ with different mass of $\mathrm{AgNO}_{3}$ was estimated to be around $50 \mathrm{~nm}$ for that of $0.5 \mathrm{~g}$ of $\mathrm{AgNO}_{3}$ with well distribution and needle shaped. In addition, for that of $0.4 \mathrm{~g}$ of $\mathrm{AgNO}_{3}$ was estimated to be smaller with similar shapes for both concentrations, as shown in Fig. 3 and 4, respectively.

This indicates that the diameters of nanomaterials can be controlled directly by the appropriate selection of parameters. In addition, nanomaterials obtained by our method all show similar range of diameters up to several nanometers. Different shapes and different composites can also be produced by gamma irradiation $\mathrm{Ag} /$ polystyrene nanorod and CdS/PVP quantum dots, which was prepared by our research group (Jan et al., 2004; Gasaymeh et al., 2010). The formation, size and distribution of $\mathrm{Ag}$ nanoparticles were controlled by varying the dose as shown in the TEM images, which satisfies our objectives. 


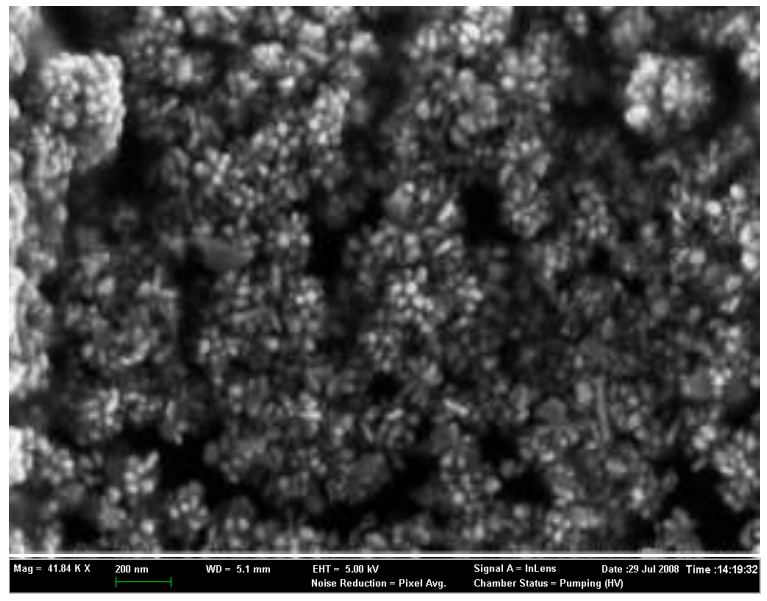

Fig. 3: STEM micrograph of Ag nanoparticles in PVP solution prepared at $40 \mathrm{kGy}$ with $0.5 \mathrm{~g}$ of $\mathrm{AgNO}_{3}$

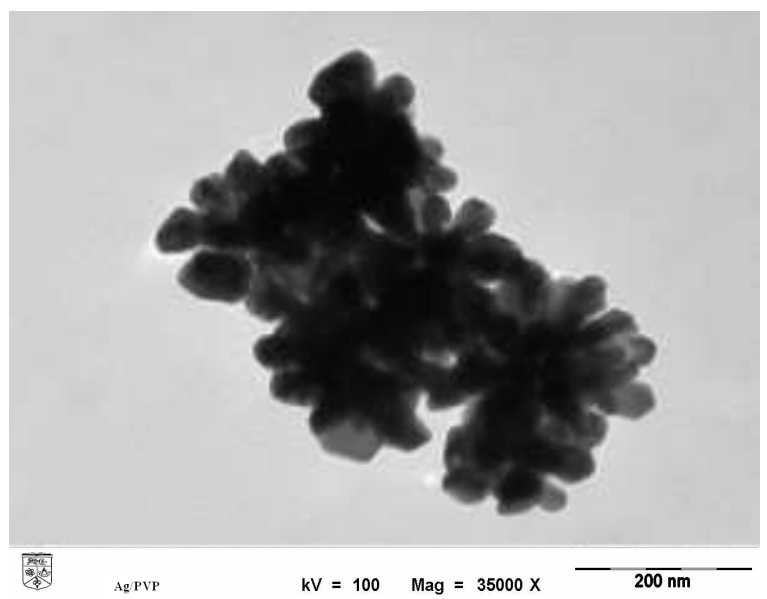

Fig. 4: TEM micrograph of Ag nanoparticles in PVP solution prepared at $40 \mathrm{kGy}$ with $0.4 \mathrm{~g}$ of $\mathrm{AgNO}_{3}$

Effect of gamma irradiation and $\mathrm{AgNO}_{3}$ concentration on the optical band gap energy by using UV-VIS spectra: Figure 5 shows the UV-VIS absorption spectra (A): For different wt $\%$ of $\mathrm{AgNO}_{3}$ $(0.7,1.5,2.1,2.9$ and 3.6) and (B): for different Gamma dose ranging from 10-50 kGy in a step of $10 \mathrm{kGy}$. All samples of $\mathrm{Ag} / \mathrm{PVP}$ nanoparticles were dispersed in the absolute ethanol and carried out by using the absolute ethanol as reference. The UV-VIS absorption spectra further indicates the formation of $\mathrm{Ag}$ nanoprticales via gamma irradiation. The characteristic peak of the $\mathrm{Ag}$ nanoparticles appears in the range of 400 to around 440 $\mathrm{nm}$, depending on the value of gamma doses which is caused by surface Plasmon resonance (Xing et al., 2006).

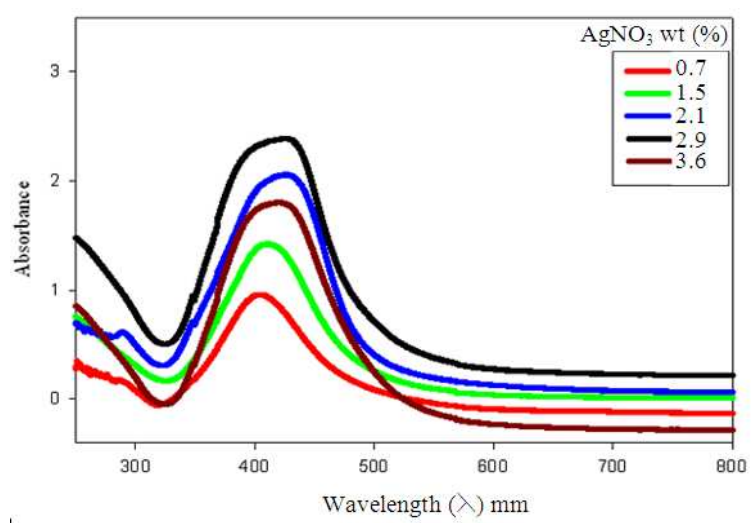

(A)

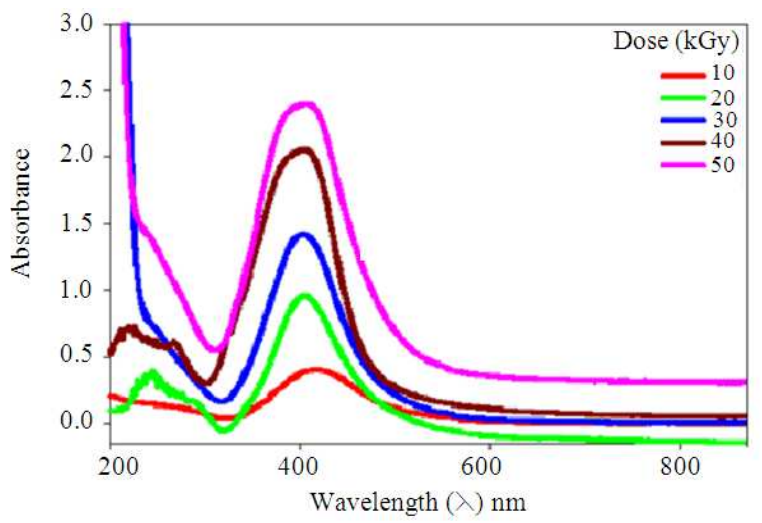

(B)

Fig. 5: UV-VIS absorption spectra (A): For different weight of (wt \%) $\mathrm{AgNO}_{3}$ (B): for different Gamma dose

The surface Plasmon phenomena, i.e. cloud electromagnetic waves coupled with the $\mathrm{CB}$ electrons, shows the peak at $440 \mathrm{~nm}$ shifting to lower wavelength, indicating a decrease of grain sizes of $\mathrm{Ag}$ nanoparticles within the PVP solution following the reduction at higher doses $\left(\pi^{*} \leftarrow \pi\right.$ transition). It is well known that the surface Plasmon resonance bands of metal nanoparticles are sensitive to their surrounding environment absorption of the electrons in the conduction bands of silver. Surface Plasmon bands appearing in the visible region are characteristic of the noble metal nanoparticles. Surface Plasmons are collective oscillations of free electrons at metallic surfaces.

The peak is seen in Fig. 5B, which shows that the Plasmon absorption peak appeared around $430 \mathrm{~nm}$ for that sample prepared at $10-\mathrm{kGy}$, shifted to lower wavelength with the increase of the gamma dose influence and subsequently reached around $410 \mathrm{~nm}$ for that sample prepared at $50 \mathrm{kGy}$. In addition, as shown 
in Fig. 5A the peak is shifted to higher wavelength as $\mathrm{AgNO}_{3}$ continents increase. Further, there are two absorption peaks as shown in Fig. 5a and b, where the weak one is at around $280 \mathrm{~nm}$ and the prominent one at around $415 \mathrm{~nm}$. The absorption peak at $280 \mathrm{~nm}$ is associated with $\mathrm{NO}_{3}$ compound, which increases with the dose influence due to the consumption of $\mathrm{Ag}^{+}$. The absorbance band at $415 \mathrm{~nm}$ is attributed to the surface Plasmon resonance phenomenon of free electrons in the conduction bands of $\mathrm{Ag}$ nanoparticles. This result is in complete agreement for that Ag nanoparticles prepared by chemical reaction (Khanna et al., 2005b).

The intensity of these bands was increased as dose or/and as the $\mathrm{AgNO}_{3}$ continents increase in the system indicating more reduction of $\mathrm{AgNO}_{3}$ to $\mathrm{Ag}$ nanmoparticles as the mentioned parameters $\left(\mathrm{AgNO}_{3}\right.$ and $\gamma$-dose) increased evidenced by Fig. 6A and B, respectively.

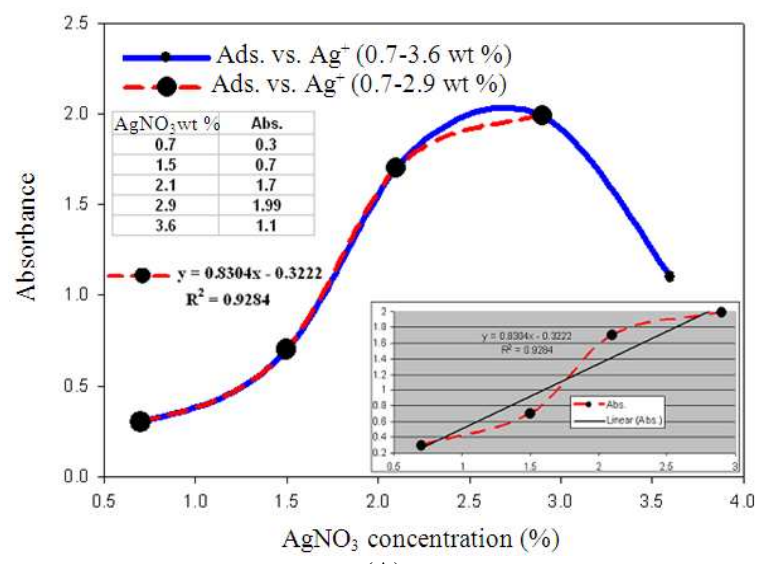

(A)

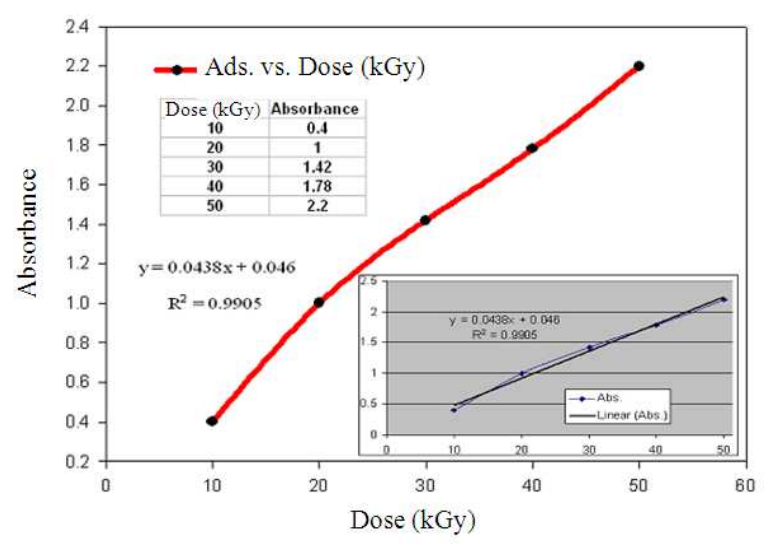

(B)

Fig. 6: Plot of absorbance Vs (A): different concentration of $\mathrm{AgNO}_{3}$, (B): different gamma dose (kGy)
The band gap of a material is defined as the energy distance between the valence and Conduction Bands (CB). The smaller the band gap, the more electrically conductive a material will be. Metals have small band gaps whereas insulators have larger band gaps, which explains why there are so few electrons found in their conduction bands. There is not sufficient energy to excite electrons from the valence band to the conduction band in the case of insulators. Semiconductors occupy a middle ground and have tractable band gaps, which when given enough thermal energy can excite electrons into the conduction band. One can also add dopants to polymers like cadmium sulfide quantum dots, silver nanoparticles that make a polymer behave more like a semiconductor or a conductor by introducing additional energy levels within the band gap. The organization of energy levels is quite different between nanomaterials and bulk materials in those nanomaterials have larger band gaps and consist of more discrete energy levels. This observation may be attributed to the various quantum confinement effects within nanoparticles whose sizes can be as small as only a few dozen atoms wide (couple of nanometers). Generally, the optical band gap energy in a semiconductors is determined by plotting absorption coefficient $\alpha(v)$ as $(\alpha(v) h v)^{1 / m}$ Vs hv where $\mathrm{m}$ represents the nature of the transition and hv is the photon energy. In addition, $m$ may have different values, such as $1 / 2,2,3 / 2$ or 3 for allowed direct, allowed indirect, forbidden direct and forbidden indirect transitions, respectively.

Practically, at the room temperature, the optical absorption spectra (UV-VIS) measurement is in the wavelength region of 190-900 $\mathrm{nm}$. This evaluation was done at $415 \mathrm{~nm}$ using Mott and Davis concept for the direct optical band gap energy for those samples prepared with 0.1-0.5 $\mathrm{g}$ of $\mathrm{AgNO}_{3}$ in a step of $0.1 \mathrm{~g}$ (0.7-3.6 wt \%) in PVP at $30 \mathrm{kGy}$ doses. Where the band gap energy may be determined from the extrapolation of the linear section of the curves to $\mathrm{x}$-axis in which $(\alpha(v) h v)^{2}=0$. This will give the band gap energies of the surface Plasmon resonance absorption of the electrons in the conduction bands of silver $\mathrm{Ag}$ nanoparticles induced by $\gamma$-irradiation at various dopant concentrations $\left(\mathrm{AgNO}_{3}\right)$, as shown in Fig. 7 .

The band gap energy decreases following the $\mathrm{AgNO}_{3}$ concentration from $2.71 \mathrm{eV}$ at $0.7 \mathrm{wt} \%$ of $\mathrm{AgNO}_{3}$ to $2.2 \mathrm{eV}$ at 2.9 wt $\%$ of $\mathrm{AgNO}_{3}$ and then shows an increase to $2.38 \mathrm{eV}$ when the dopant concentration of $\mathrm{AgNO}_{3}$ is increased to $3.6 \mathrm{wt} \%$ as presented in Fig. 7. In addition, the result showed a strong dependence on the concentration of the $\mathrm{AgNO}_{3}$ dopant showing a minimum value of band gap for the sample 
doped with a concentration of 2.9 wt $\%$ of the $\mathrm{AgNO}_{3}$ dopant as illustrated in Fig 8. Above this concentration of $2.9 \mathrm{wt} \%(3.6 \mathrm{wt})$, the band gap energy increases continuously with increasing $\mathrm{AgNO}_{3}$ dopant concentration. The decrease in optical band gap on doping up to a dopant concentration 2.9 wt \% may be explained on the basis of the fact that the incorporation of small amounts of dopant forms Charge Transfer Complexes (CTCs) in the host lattice.

The optical band gaps were evaluated also for those samples prepared at different gamma irradiation doses ranging from 10-50 kGy in a step of 10-kGy at a given constant $\mathrm{AgNO}_{3}$, as presented in Fig. 9. It is clear from the result that the band energy showed a decrease as the dose increased. Such decrease in the band gap is attributed to more reduction of $\mathrm{AgNO}_{3}$ to $\mathrm{Ag}$ nanoparticles similar assumption made by (Niu et al., 2003; Devendrappa et al., 2006) and the particle go smaller as the dose is increased, as shown by the TEM imaging. The effect of surface Plasmon, which splits to discrete in the band gap of the composite leading to decrease in the general band, gap (Zhu, 2005).

Figure 10 shows a plot of the band gap energy decreasing following the radiation dose increment from $2.62 \mathrm{eV}$ for that prepared at $10 \mathrm{kGy}$ to $2.23 \mathrm{eV}$ for that sample prepared at 50-kGy.

Effect of gamma irradiation and $\mathrm{AgNO}_{3}$ concentration on the thermal properties by using Thermo Gravimetric (TGA): TGA measurements were carried out on the Ag/PVP nanocomposites and pure PVP. A known weight of the samples was heated at a rate of $10^{\circ} \mathrm{C} \mathrm{min}^{-1}$ from room temperature up to $600^{\circ} \mathrm{C}$, which is in between the boiling point of the solvent and the degradation temperature of the polymer. Figure 11, shows two distinct stages of weight loss were observed, an initial weight loss was calculated to be around 13.1 and $14.2 \% \mathrm{Ag} / \mathrm{PVP}$ and PVP respectively in the range of room temperature up to $250^{\circ} \mathrm{C}$.

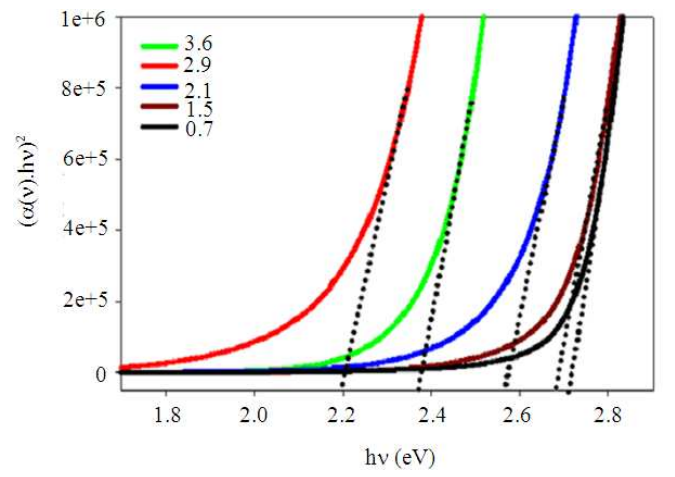

Fig. 7: Variation of direct allowed transition using Mott and Davis concept for PVP/Ag composite at $415 \mathrm{~nm}$ at different $\mathrm{AgNO}_{3}$ concentration
The weight loss up to this range of temperature is attributed to low molecular weight oligomers, loss of moisture and residual solvent in this range of temperature.

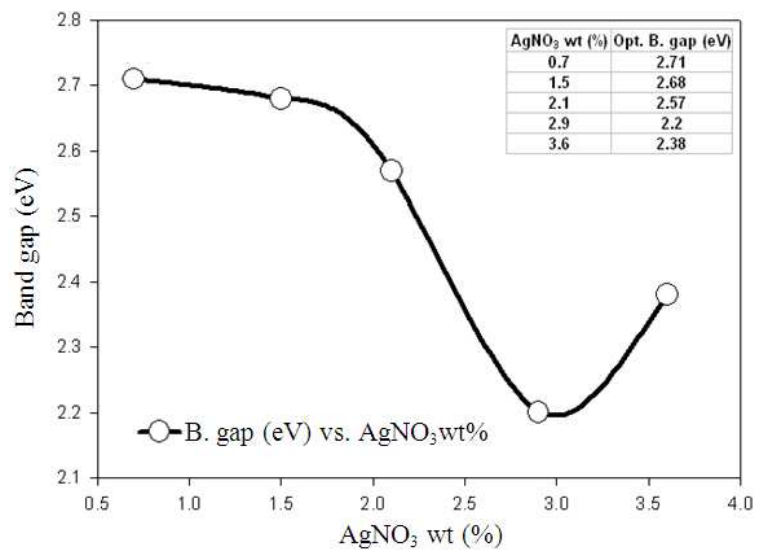

Fig. 8: The variation of band gap energy for $\mathrm{Ag}$ nanoparticles in PVP at different $\mathrm{AgNO}_{3}$ concentration $(\%)$

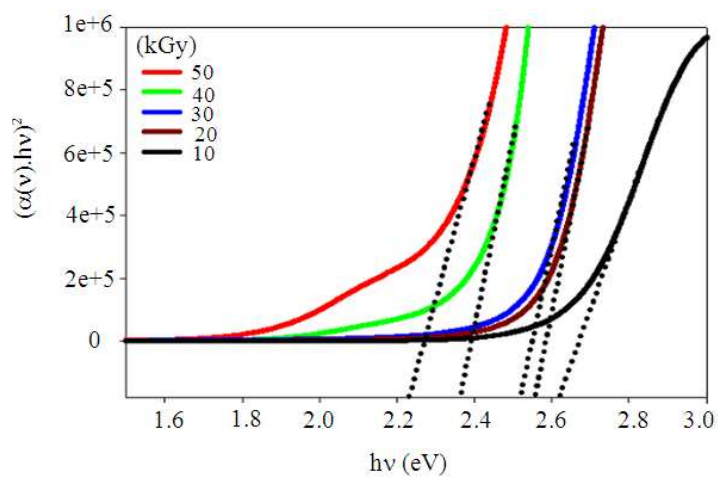

Fig. 9: The variation of direct allowed transition using Mott and Davis concept for PVP/Ag nanocomposite at $415 \mathrm{~nm}$ prepared at different doses

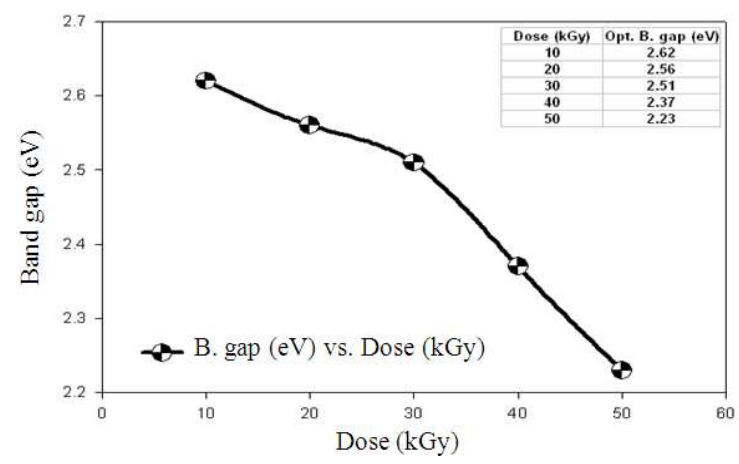

Fig. 10: The variation of band gap energy for $\mathrm{Ag}^{+}$ nanoparticles in PVP at different doses 
Am. J. Applied Sci., 7 (7): 892-901, 2010

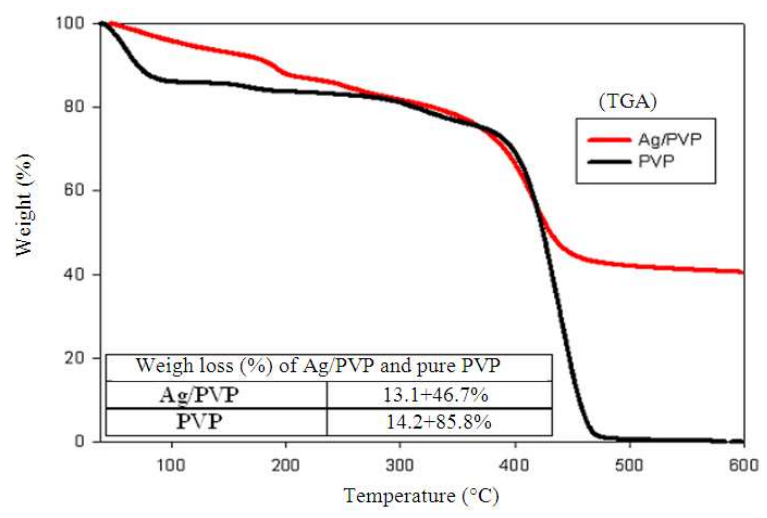

Fig. 11: The TGA thermogram of Ag/PVP nanoparticles and pure PVP, where, the weight loss from TGA thermogram results at first and second stages is illustrated

The second weight loss indicates that the pure PVP began to degrade above $300^{\circ} \mathrm{C}$ and is completely decomposed at above $500^{\circ} \mathrm{C}$. The second major weight loss was attributed to structural decomposition of polymer. The weight loss of Ag/PVP nanoparticles and pure PVP is tabulated in Fig. 11. However, the thermo gravimetric analysis of the Ag/PVP nanocomposite showed decomposition profile starting at about $350^{\circ} \mathrm{C}$ and continuing until about $480^{\circ} \mathrm{C}$. This shows that the thermal stability of the polymer is improved due to presence of $\mathrm{Ag}$ as nano-filler. This observation is consistent with the results obtained by (Mbhele et al., 2003), where it has been shown that the PVA alone starts decomposing at about $280^{\circ} \mathrm{C}$ and its composite with about $<1 \% \mathrm{Ag}$ starts decomposing at higher temperature than the PVA alone, typically about $40^{\circ} \mathrm{C}$ more. In our experiments, though the content of $\mathrm{Ag}$ is expected to be more but it appears that the degradation temperature of our composite is higher to that it is reported.

\section{DISCUSSION}

However, comparing our results with those previous studies may be used as a discussion on the subject. Handful of published papers (Li et al., 2006; Wu et al., 2005; Jia et al., 2006; Liu et al., 2006) successfully synthesized $\mathrm{Ag}$ nanoparticles using electron irradiation of silver acetate, obtained the particle size about $40 \mathrm{~nm}$ and by using $\gamma$-irradiation, 30 $\mathrm{nm}$ of $\mathrm{Ag}$ nanoparticles was successfully obtained. Moreover, it was reported in the same experiment that the diameter of Ag nanoparticles tends to reduce in size with the increase of dose. Moreover, similar result was obtained by the reduction of $\mathrm{AgNO}_{3}$ by sodium citrate under light irradiation with average size of $100 \mathrm{~nm}$. Using the chemical method on reduction of $\mathrm{AgNO}_{3}$ in the presence of sodium Polyglutamic Acid (PGA) in PVP matrix, similar results of $20 \mathrm{~nm} \mathrm{Ag}$ nanoparticles were obtained by (Jing et al., 2006; Yu et al., 2007). Earlier Ag nanoparticles have been synthesized in Polymethylmethacrilate (PMMA) by $30 \mathrm{kV} \mathrm{Ag}^{+}$ion implantation, which produces $\mathrm{Ag}$ nanoparticles with sizes from 2-20 nm (Mishra et al., 2007). Therefore, similar with the formation of nanocomposites discussed above, the diameter of nanoparticles induced by $\gamma$ radiation in PVP binder is dependent on the type of binder and radiation dose with respect to the other parameters.

In the case of the UV-VIS, the blue shift in the Plasmon absorption peak reveals that the size of the nanoparticles decreases with increasing gamma dose influence as witnessed from TEM micrographs. Further, the intensity of the absorption bands, which is proportional to the number of silver nanoparticles, goes higher, indicates that more reduction of $\mathrm{AgNO}_{3}$ to $\mathrm{Ag}$ nanoparticale as the dose increases. Similar result was observed by (Bogle et al., 2006) for Ag/PVA prepared by electron irradiation. In addition, similar result was observed as we increase the amount of $\mathrm{AgNO}_{3}$ in the composite. The intensity of absorption spectra goes higher but there was a slight shift to higher wavelength as $\mathrm{AgNO}_{3}$ continents increased in the composites indicating more reduction of $\mathrm{AgNO}_{3}$ to $\mathrm{Ag}$ nanoparticles.

These oscillations can give rise to the intense colors for Plasmon resonance nanoparticles in PVP. When many Ag are in close proximity, they are able to interact electromagnetically through a dipole-dipole coupling mechanism (Hutter and Fendler, 2004). Our result is in agreement with the reported study by (Porel et al., 2005) who investigated the formation of $\mathrm{Ag}$ nanoparticles in solution containing $1 \mathrm{mM} \mathrm{AgNO}$, $1 \mathrm{mM}$ sodium citrate and ethanol $(0.025 \mathrm{~mL})$ irradiated by $\gamma$-rays. Our results also indicate that as the dose was increased, the surface Plasmon resonance peak at 415 $\mathrm{nm}$ shifted towards lower wavelength, indicating smaller diameters of the $\mathrm{Ag}$ nanoparticles were also formed at higher radiation doses; the wave length was shifted to higher wave as the $\mathrm{AgNO}_{3}$ increased. Similar result was observed in previous studies by (Bogle et al., 2006). The observation of decreasing in band gap for doped samples may be attributed to the fact that their charge transfer complexes increase the electrical conductivity by providing additional charges in the polymer lattice due to the corporation of $\mathrm{Ag}$ nanoparticles with PVP by the influence of gamma irradiation, which is going to be discussed later. 
However, in further addition of $\mathrm{AgNO}_{3}$ dopant concentration, it leads to segregation of the dopant in the host matrix. These molecular aggregates impede the motion of charge carriers resulting in a decrease in their conductivity and hence increasing optical band gap energy. Similar results have been reported by (Bhat and Kelkar, 1990) on the effect in copper chloride-doping nylon-6 films. These results point to the fact that a dopant concentration up to 2.9 wt $\%$ is the critical concentration that gives optimum values for the optical properties. The incorporation of metal nanoparticles could effectively improve the electrical, optical and dielectric properties of the polymer composites (Yakuphanoglu et al., 2006; Sarma et al., 2002). These properties are very much sensitive to small changes in the metal content and in the size and shape of the nanoparticles. It was reported that the nanoparticles themselves could act as conductive junctions between the polymer chains that resulted in an increase of the electrical conductance of the composites (Gangopadhyay and Amitabha, 2000; Del CastilloCastro et al., 2007) in which leads to a decrease in their optical band gap energy. The morphology and the particle size may play an important role in the optical absorption spectra of the Ag/PVP nanoparticles. The entire above calculated band gap samples have different particle size as shown by the TEM micrographs. The absorption peak due to the surface Plasmon resonance of the Ag particles can be observed at around $430 \mathrm{~nm}$ as shown in Fig. 5, as the volume fraction of $\mathrm{Ag}$ increases the surface Plasmon resonance peak shifts toward longer wavelengths. The shift of the surface Plasmon resonance peak position is accompanied by an increase of the absorbance and the width of the peak. As is well known, the surface Plasmon resonance absorption is sensitive to the microstructure of the sample, i.e., size and shape of the dispersed metal particles, concentration of metal phase and dielectric constant of host medium (Tjong and Liang, 2006). In addition, irradiation may change the direction of polarization, this change in the direction of polarization lowers the value of dielectric and as a result, their band gap energy will be reduced. In addition, the size was change following the dose increment, the size dependence of the surface Plasmon resonance peak position is explained by a size-dependent effective dielectric constant of a metal particle due to the interactions of conduction electrons (Bogle et al., 2006; Tjong and Liang, 2006). When the particles become much smaller than the mean free path of conduction electrons in the bulk metal, the effective mean free path becomes the dimensions of the particle because electrons are scattered at particle surface. Since the mean size of the
Ag particles $(\sim 8 \mathrm{~nm})$ produced by our method is much smaller than the mean free path of bulk silver $(\sim 52 \mathrm{~nm})$, such effect must be significant.

However, the morphology (particle sizes) could play a strong role in conductivity, which as a result affects both the dielectric loss and dielectric constant (this will be discussed later). Large particle size leads to electron tunneling while smaller size results in small polaron tunneling and these smaller ones increases with increasing the irradiation doses. As a result of that their band gap energy may decrease to lower value. The shift of the band gap position observed in the present study is probably due to the change of the size of the $\mathrm{Ag}$ nanoparticles from $\sim 6$ to $\sim 50 \mathrm{~nm}$. The present technique (gamma irradiation) leads to a simultaneous increase of the volume fraction with decreasing size of the $\mathrm{Ag}$ nanoparticles as evidence from the TEM images. In addition, irradiation of Ag/PVP samples leads to formation of $\mathrm{Ag}$ nanoparticles and chemical change in polymer chain, namely, chain scission and crosslinking, which all lead to improve optical properties (Virk and Srivastava, 2001; Singh et al., 2008; Steckenreiter et al., 1997). The inter-particle distance decreased as more $\mathrm{Ag}$ is incorporated and as dose is increased, both factors can decrease the band gap of the composites. All these results are explained based on the morphologies of these composites as revealed by the TEM study mentioned above. As indicated by the TEM micrograph, the majority of nano-size Ag/PVP particles were well dispersed in the PVP when the Ag content rang from 0.1-0.4 g (0.7-2.9 wt\%) synthesized at higher gamma dose. Since the changes in the volume fraction of metal particles in the sample leads to a change of the dielectric constant of the composite due to electromagnetic interaction between neighboring particles. This effect is also thought to be responsible for the change of the band gap as has been shown previously by (Bogle et al., 2006; Liu et al., 2006) in the shift in the surface Plasmon resonance peak. Therefore, it seems likely that the observed changes in optical absorption spectra for the Ag/PVP nanoparticles can be qualitatively explained by the changes in the effective dielectric constant of the Ag/PVP nanocomposite due to different size and volume fraction of the Ag particles in the PVP, which ends with the same effect on their band gap.

The thermal stability is one of the most important and inter related variable, in which must be carefully considered when a material is chosen for the synthesis of organic electronic devices. There appears to be an optimal concentration of $\mathrm{Ag}$ nanoparticles in PVP, which maximizes the thermal properties of the materials. Sample with $0.5 \mathrm{~g}$ of $\mathrm{AgNO}_{3}$ was found to be 
the most suitable and thermal stable. Therefore, the optimized Ag/Polymer nanocomposites materials have the potential to produce organic electronic device capable of higher thermal stability than pure polymer, leading to many useful application in organic electronics and nanotechnology.

\section{CONCLUSION}

This result indicates that $\mathrm{AgNO}_{3}$ can effectively dope PVP and enhance the optical and thermal properties. In addition, $\gamma$-irradiation is an effective technique for preparing inorganic/organic nanocomposites. The improvement in the optical properties may attribute to irradiation with $\gamma$-ray that leads to the formation of $\pi$-electron clouds, with the polarization aligned in the direction of the molecular chains (Bhat and Kelkar, 1990).

\section{ACKNOWLEDGEMENT}

We thank the Faculty of Science and Technology University Kebangsaan Malaysia (UKM) for their valuable advice and support. We also acknowledge (UKM) in providing instrumentation facilities and grant UKM-OUP-NBT-28-138/2009, which made it possible for this study to be conducted. In addition, S.S. Gasaymeh would like to thank Eng. Jawdat Salameh Kasaymeh for his financial support.

\section{REFERENCES}

Basavaraja, C., R. Pierson and D.S. Huh, 2008a. Synthesis, characterization and comparative study of conducting polyaniline/lead titanate and polyaniline-dodecylbenzenesulfonic acid/lead titanate composites. J. Applied Polymer Sci., 108: 1070-1078. DOI: 10.1002/app.27582

Basavaraja, C., R. Pierson, T.K. Vishnuvardhan and D.S. Huh, 2008b. Characterization and electrical behavior of polyaniline-poly-Nisopropylacrylamide-co-acrylic acid/alumina aqueous dispersions in the presence of dodecyl benzenesulfonic acid. Eur. Polymer J., 44: 1556-1566. DOI:10.1016/j.eurpolymj.2008.02.015

Baughman, R.H., J.F. Wolf, H. Eckhardt and L.W. Shacklette, 1988. The structure of a novel polymeric metal: Acceptor-doped polyaniline. Synth. Metals, 25: 121-137. DOI: 10.1016/0379-6779(88)90348-7

Bhat, N.V. and D.S. Kelkar, 1990. Investigation of electrical conductivity of nylon-6 films doped with copper chloride. J. Phys. D: Applied Phys., 23: 899-902. DOI: 10.1088/0022-3727/23/7/022
Bogle, K.A., S.D. Dhole and V.N. Bhoraskar, 2006. Silver nanoparticles: Synthesis and size control by electron irradiation. Nanotechnology, 17: 3204-3208. DOI: $10.1088 / 0957-4484 / 17 / 13 / 021$

Del Castillo-Castro, T., E. Larios-Rodriguez, Z. MolinaArenas, M.M. Castillo-Ortega and J. Tanori, 2007. Synthesis and characterization of metallic nanoparticles and their incorporation into electroconductive polymer composites. Composites: Part A: Applied Sci. Manuf., 38: 107-113. DOI: 10.1016/j.compositesa.2006.01.011

Devendrappa, H., U.V. Subba Rao and M.V.N. Ambika Prasad, 2006. Study of dc conductivity and battery application of polyethylene oxide/polyaniline and its composites. J. Power Sources, 155: 368-374. DOI: 10.1016/j.jpowsour.2005.05.014

Gangopadhyay, R. and D. Amitabha, 2000. Conducting polymer nanocomposites: A brief overview. Chem. Mater., 12: 608-622. DOI: 10.1021/cm990537f

Gasaymeh, S.S., S. Radiman, L.Y. Heng and E. Saion, 2010. Gamma Irradiation synthesis and Influence the Optical and Thermal Properties of Cadmium sulfide (CdS)/Poly (vinyl pyrolidone) Nanocomposites. Am. J. Applied Sci., 7: 500-508.

Hutter, E. and J.H. Fendler, 2004. Exploitation of localized surface Plasmon resonance. Adv. Mater., 16: 1685-1706. DOI: 10.1002/adma.200400271

Jan, L.S., S. Radiman, M.A. Siddig, S.V. Muniandy, M.A. Hamid and H.D. Jamali, 2004. Preparation of nanoparticles of polystyrene and polyaniline by $\gamma$ irradiation in lyotropic liquid crystal. Colloids Surfaces A: Physicochem. Eng. Aspects, 251: 43-52. DOI: 10.1016/j.colsurfa.2004.09.025

Jia, H., J. Zeng, W. Song and B. Zhao, 2006. Preparation of silver nanoparticles by photoreduction for surface-enhanced Raman scattering. Thin Solid Films, 496: 281-287. DOI: 10.1016/j.tsf.2005.08.359

Jing, S., S. Xing, L. Yu, Y. Wu and C. Zhao, 2006. Synthesis and characterization of $\mathrm{Ag} /$ polyaniline core-shell nanocomposites based on silver nanoparticles colloid. Mater. Lett., 61: 2794-2797. DOI: $10.1016 /$ j.matlet.2006.10.032

Kang, Y.O., S.H. Choi, A. Gopalan, K.P. Lee, H.D. Kang and Y.S. Song, 2006. Tuning of morphology of $\mathrm{Ag}$ nanoparticles in the Ag/polyaniline nanocomposites prepared by $\gamma$-ray irradiation. J. Non-Crystall. Solids, 352: 463-468. DOI: 10.1016/j.jnoncrysol.2006.01.043

Karim, M.R., K.T. Lim, C.J. Lee, M.T.I. Bhuiyan and H.J. Kim et al., 2007. Synthesis of core-shell silver-polyaniline nanocomposites by gamma radiolysis method. J. Polymer Sci.: Part A: Polymer Chem., 45: 5741-5747. DOI: 10.1002/pola.22323 
Khanna, P.K., N. Singh, S. Charan, V.V.V.S. Subbarao, R. Gokhale and U.P. Mulik, 2005a. Synthesis and characterization of Ag/PVA nanocomposite by chemical reduction method. J. Mater. Chem. Phys., 93: 117-121. DOI: 10.1016/j.matchemphys.2005.02.029

Khanna, P.K., N. Singh, S. Charan and A.K. Viswanath, 2005b. Synthesis of Ag/polyaniline nanocomposite via an in situ photo-redox mechanism. Mater. Chem. Phys., 92: 214-219. DOI: 10.1016/j.matchemphys.2005.01.011

Lebaron, P.C., Z. Wang and T.J. Pinnavaia, 1999. Polymer-layered silicate nanocomposites: An overview. Applied Clay Sci., 15: 11-29. DOI: 10.1016/S0169-1317(99)00017-4

Li, J., L. Zhu, Y. Wu, Y. Harima, A. Zhang and H. Tang, 2006. Hybrid composites of conductive polyaniline and nanocrystalline titanium oxide prepared via selfassembling and graft polymerization. Polymer, 47: 7361-7367. DOI: 10.1016/j.polymer.2006.08.059

Liu, Z.H., X.J. Yang, Y. Majita and O. Kenta, 2006. Preparation of a polycation-intercalated layered manganese oxide nanocomposite by a delamination/reassembling process. Chem. Mater., 14: 4800-4806. DOI: $10.1021 / \mathrm{cm} 020652 \mathrm{~h}$

Mbhele, Z.H., M.G. Salemane, C.G.C.E. van Sittert, J.M. Nedeljkovic, V. Djokovic and A.S. Luyt, 2003. Fabrication and characterization of silverpolyvinyl alcohol nanocomposites. J. Chem. Mater., 15: 5019-5025. DOI: 10.1021/cm034505a

Mishra, Y.K., S. Mohapatra, D. Kabiraj, B. Mohanta and N.P. Lalla et al., 2007. Synthesis and characterization of $\mathrm{Ag}$ nanoparticles in silica matrix by atom beam sputtering. Scripta Metrialia, 56: 629-632. DOI: 10.1016/j.scriptamat.2006.12.008

Niu, L., Q.H. Li, F.H. Wei, X. Wei and H. Wang, 2003. Electroactivity of electrochemically synthesized poly(aniline boronic acid) as a function of $\mathrm{pH}$ : Role of self-doping. J. Electroanal. Chem., 544: 121-125. DOI: 10.1021/cm035296x

Park, S.J., D.I. Seo and J.R. Lee, 2002. Surface modification of montmorillonite on surface acidbase characteristics of clay and thermal stability of epoxy/clay nanocomposites. J. Colloid Interface Sci., 251: 160-165. DOI: 10.1006/jcis.2002.8379

Porel, S., S. Singh, S.S. Harsha and D.N. Rao, 2005. Nanoparticle-embedded polymer: In situ synthesis, free-standing films with highly monodisperse silver nanoparticles and optical limiting. Chem. Mater., 17: 9-12. DOI: $10.1021 / \mathrm{cm} 0485963$

Qiao, Z., Y. Xie, J. Huang, Y. Zhu and Y. Qian, 2000. Single-step confined growth of CdSe/polyacrylamide nanocomposites under $\gamma$ irradiation. J. Radiat. Phys. Chem., 58: 287-292. DOI: 10.1016/S0969-806X(99)00465-X
Qiao, Z., Y. Xie, X. Li, C. Wang, Y. Zhu and Y. Qian, 1999. $\gamma$-Irradiation preparation and phase control of nanocrystalline CdS. J. Mater. Chem., 9: 735-738. DOI: $10.1039 / \mathrm{a} 807757 \mathrm{f}$

Sarma, T.K., D. Chowdhury, A. Paul and A. Chattopadhyay, 2002. Synthesis of $\mathrm{Au}$ nanoparticle-conductive polyaniline composite using $\mathrm{H}_{2} \mathrm{O}_{2}$ as oxidizing as well as reducing agent. Chem. Commun., 14: 1048-1049. DOI: $10.1039 / \mathrm{b} 201014 \mathrm{c}$

Singh, R., K.S. Samra, R. Kumar and L. Singh, 2008. Microstructural modifications in swift ion irradiated PET. J. Radiat. Phys. Chem., 77: 575-580. DOI: 10.1016/j.radphyschem.2007.06.014

Steckenreiter, T., E. Balanzat, H. Fuess and C. Trautmann, 1997. Damage and track morphology in $\mathrm{LiF}$ crystals irradiated with $\mathrm{GeV}$ ions. Phys. Rev. B., 58: 11232-11240. DOI: 10.1103/PhysRevB.58.11232

Tjong, S.C. and G.D. Liang, 2006. Electrical properties of low-density polyethylene/ $\mathrm{ZnO}$ nanocomposites. Materials Chem. Phys., 100: 1-5. DOI: 10.1016/j.matchemphys

Virk, H.S. and A.K. Srivastava, 2001. Modification of optical, chemical and structural response of CR-39 polymer by $50 \mathrm{MeV}$ lithium ion irradiation. J. Radiat. Measure., 34: 65-67. DOI: 10.1016/S13504487(01)00122-6

Wu, W.T., Y. Wang, L. Shi, Q. Zhu and W. Pang et al., 2005. Fabrication of silver/cross-linked poly (vinyl alcohol) cable-like nanostructures under $\gamma$-ray irradiation. Nanotechnology, 16: 3017-3022. DOI: 10.1088/0957-4484/16/12/048

Xing, S., C. Zhao, S. Jing and Z. Wang, 2006. Morphology and conductivity of polyaniline nanofibers prepared by 'seeding' polymerization. Polymer, 47: 2305-2313. DOI: 10.1016/j.polymer.2006.02.008

Yakuphanoglu, F., E. Basaran, B.F. Senkal and E. Sezer, 2006. Electrical and optical properties of an organic semiconductor based on polyaniline prepared by emulsion polymerization and fabrication of Ag/polyaniline/n-Si Schottky diode. J. Phys. Chem. B., 110: 16908-16913. DOI: 10.1021/jp060445v

Yu, D.G., W.C. Lin, C.H. Lin, L.M. Chang and M.C. Yang, 2007. An in situ reduction method for preparing silver/poly(vinyl alcohol) nanocomposites as Surface-Enhanced Raman Scattering (SERS)active substrates. Mater. Chem. Phys., 101: 93-98. DOI: 10.1016/j.matchemphys.2006.02.020

Zhu, J., 2005. Theoretical study of the optical absorption properties of Au-Ag bimetallic nanoparticles. Phys. E., 27: 296-301. DOI: 10.1016/j.physe.2004.12.006 